\title{
Sistem Pakar Diagnosa Penyakit pada Sapi Berbasis Android
}

\author{
Yulyanto \\ Fakultas Ilmu Komputer Universitas Kuningan \\ Jalan Tjut Nyak Dhien No. 36 A Cijoho Kuningan Jawa Barat 45513 Telepon (0232) 2875097 \\ yulyanto@uniku.ac.id
}

\begin{abstract}
Abstrak
Penanganan gangguan reproduksi pada tingkat usaha tani masih kurang, karena kurangnya informasi tentang pengobatan ternak yang memiliki dampak yang signifikan terhadap penurunan produksi daging. Untuk mengurangi dampak penyakit reproduksi, maka perlu untuk melakukan deteksi dan pengobatan dini untuk mencegah kerugian tinggi dan penyebaran yang lebih luas dari penyakit. artikel ini menjelaskan Penerapan sistem pakar yang menyediakan sarana konsultasi yang meniru proses penalaran seorang pakar dalam memecahkan masalah yang kompleks mengenai kesehatan reproduksi sapi. Dalam penelitian ini akan diterapkan metode Tsukamoto Fuzzy untuk membantu mendiagnosa tingkat risiko penyakit pada sapi berdasarkan enam gejala klinis. Hasil penelitian ini adalah sistem pakar mobile yang akan menyimpulkan tingkat risiko penyakit endometriosis pada sapi. Aplikasi ini dikembangkan berbasis android agar mudah digunakan dan dapat digunakan oleh petani dalam membuat diagnosis secara independen. Hasil pengujian sistem pakar ini menunjukkan bahwa sistem ini dapat menentukan tingkat risiko endometritis penyakit reproduksi sapi.
\end{abstract}

Kata kunci: sistem pakar, berbasis android, logika fuzzy, penyakit sapi

\section{Abstract}

Handling reproductive disorders at the farm level is still lack due to the less information about the treatment of livestock which has a significant impact on decreasing of meat production. To reduce the impact of reproductive diseases, it is necessary to carry out early detection and treatment to prevent high losses and wider spread of disease. This article describes the application of an expert system that provides a means of consultation that uses an expert's reasoning process in solving complex problems regarding to cow reproductive health. In this study, the Tsukamoto Fuzzy method will be applied to help diagnosing the risk of disease in cattle based on six clinical symptoms. The result of this study is a mobile expert system that will conclude the risk level of endometriosis in cattle. This application is developed based on Android so that it is easy to use and it can be used by farmers to make a diagnosis independently. The result of this expert system testing indicates that this system can determine the level of endometritis risk of cow reproductive disease.

Keywords: expert system, android based, fuzzy logic, cow disease

\section{PENDAHULUAN}

Keberhasilan reproduksi akan sangat mendukung peningkatan populasi sapi potong. Namun kondisi sapi potong di usaha peternakan rakyat, hingga saat ini sering dijumpai adanya kasus gangguan reproduksi yang ditandai dengan rendahnya fertilitas induk, akibatnya berupa penurunan angka kebuntingan dan jumlah kelahiran pedet, akibat gangguan reproduksi pada ternak ini akan merugikan para peternak dan secara nasional akan memperlambat laju peningkatan populasi ternak di dalam negeri.Kesehatan ternak adalah suatu keadaan atau kondisi dimana tubuh hewan dengan seluruh sel yang menyusun dan cairan tubuh yang dikandungnya secara fisiologis berfungsi normal [1].

Salah satu bagian yang paling penting dalam penanganan kesehatan ternak adalah melakukan pengamatan terhadap ternak yang sakit melalui pemeriksaan ternak yang diduga sakit. Pemeriksaan ternak yang diduga 
JURNAL NUANSA INFORMATIKA

Volume 13 Nomor 1, Januari 2019

sakit adalah suatu proses mengamati perubahan yang terjadi pada ternak melalui gejala yang nampak sehingga jenis penyakit dapat diketahui. Penanganan gangguan reproduksi ditingkat pelaku usaha peternakan masih kurang, bahkan beberapa peternak terpaksa menjual sapi dengan harga yang murah karena tidak paham cara menangani penyakit. Perlu teknologi inovatif untuk penanggulangan gangguan reproduksi sapi, khususnya pada sapi induk usaha perbibitan rakyat dengan harapan sapi induk lebih produktif dan memacu semangat untuk berusaha.

Sitem pakar adalah hasil dari teknologi yang dikembangkan dengan tujuan untuk meniru kemampuan seorang ahli dalam bidang tertentu [2]. sistem pakar memungkinkan peternak sebagai pengguna sistem dapat berkomunikasi tentang penyakit pada sistem sebagai dokter hewan tanpa dibatasi oleh jarak dan waktu dan dapat dilakukan di mana saja dan kapan saja. Pengguna akan diarahkan oleh sistem untuk menjawab gejala yang namapak pada sapi secara rinci selanjutnya sistem akan memberikan solusi terhadap masukan gejala yang disampaikan oleh pengguna. sistem pakar dengan menggunakan logika fuzzy mampu memberikan solusi untuk masalah yang mengandung unsur perkiraan seperti ketidakpastian gejala.

\section{METODOLOGI}

Aplikasi sistem pakar fuzzy ini terdiri dari 4 buah komponen yaitu; pemfuzzifikasi (fuzzifier), mesin inferensia (inference engine), defuzzifikasi (defuzzier) dan fuzzy rule base [12].

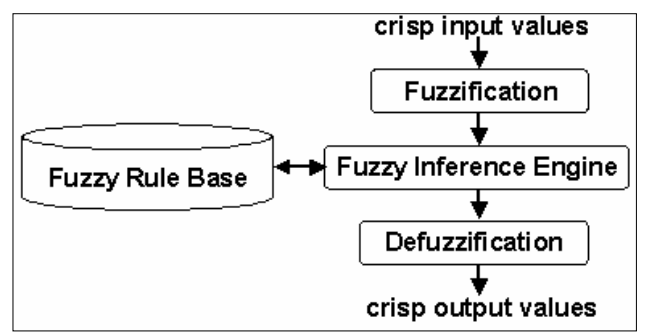

Figure 4. Model Sistem Pakar fuzzy

\subsection{Input Nilai}

Pada tahap ini

setiap input dan output akan difuzzikan menjadi variabel linguistik, terdiri dari enam variabel input dan satu variabel out put, setiap variabel di Representasi menggunakan triangular $M F$.
p-ISSN : 1858-3911, e-ISSN : 2614-5405

https://journal.uniku.ac.id/index.php/ilkom

Table 1. Himpunan Bahasa Variable

\begin{tabular}{ll}
\hline \multicolumn{1}{c}{ Variable } & \multicolumn{1}{c}{ Himpunan } \\
\hline $\begin{array}{l}\text { Suhu } \\
\text { Frekuensi }\end{array}$ & Normal, Tinggi \\
Nafas & Normal, Cepat \\
Retensio & Cepat, Lambat, Sangat \\
Sekundinae & Lambat \\
Leleran & Bening, Bening Bernanah, \\
& Bernanah \\
Urinasi & Sedikit, Normal, Sering \\
Lochia & Pendek, Normal, Panjang \\
Status & Ringan, berat, akut \\
Endometritis & \\
\hline
\end{tabular}

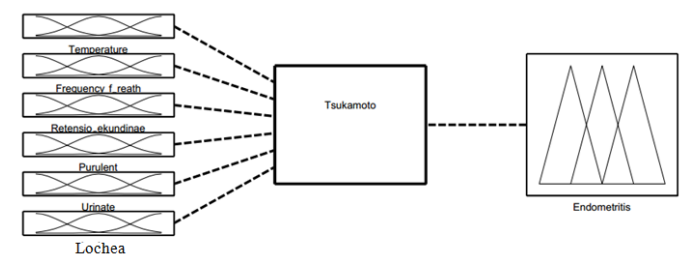

Figure 5. Proses Fuzzy Inferensi Tsukamoto

- Fungsi keanggotaan dari variabel suhu

Table 2. Linguistic Terms Used For Input Variable Temperature

\begin{tabular}{cc}
\hline Fuzzy set & Interval \\
\hline Low & {$[36,40]$} \\
High & {$[38.5,42]$} \\
\hline
\end{tabular}

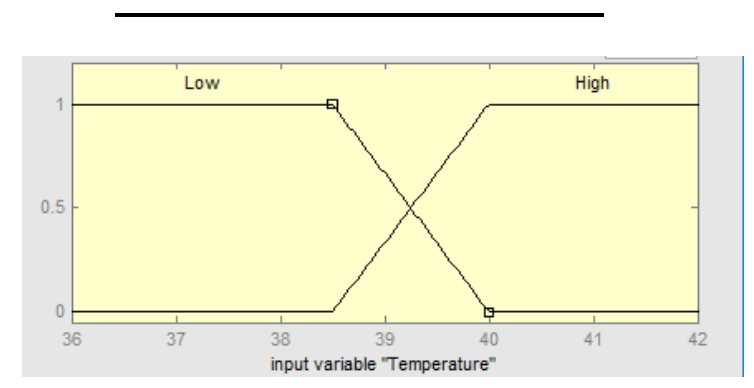

Figure 6. Membership Functions Temperature

$$
\mu_{\text {Lowl }}[x]\left\{\begin{array}{rr}
1, & 36<x \leq 38.5 \\
\frac{40-x}{1.5}, & 38.5<x<40 \\
0, & x \geq 40
\end{array}\right.
$$

$$
\mu_{H i g h}[x]\left\{\begin{array}{cc}
0, & x \leq 38.5 \\
\frac{x-38.5}{1.5}, & 38.5<x<40 \\
1, & 40 \leq x \leq 42
\end{array}\right.
$$


JURNAL NUANSA INFORMATIKA

Volume 13 Nomor 1, Januari 2019

- $\quad$ Fungsi keanggotaan dari variabel frekuensi nafas

Table 3. Linguistic Terms Used For Input Variable Frequency Of Breath

\begin{tabular}{cc}
\hline $\begin{array}{c}\text { Fuzzy } \\
\text { set }\end{array}$ & Interval \\
\hline Ideal & {$[15,40]$} \\
Fast & {$[30,60]$}
\end{tabular}

Ideal

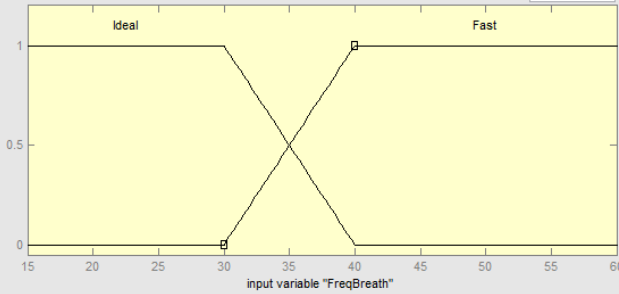

Figure 7. Fuzzy Sets Membership Functions Frequency Of Breath

$$
\mu_{\text {Ideal }}[x]\left\{\begin{array}{cc}
1, & 15 \leq x \leq 40 \\
\frac{40-x}{15}, & 30<x<40 \\
0, & x \geq 40
\end{array}\right.
$$

$$
\mu_{\text {Fast }}[x]\left\{\begin{array}{cc}
0, & x \leq 30 \\
\frac{x-30}{10}, & 30<x<40 \\
1, & 40 \leq x \geq 60
\end{array}\right.
$$

- Fungsi keanggotaan dari variabel retensio sekundinae

Table 4. Linguistic Terms Used For Input Variable Retensio Sekundinae

\begin{tabular}{cc}
\hline $\begin{array}{c}\text { Fuzzy } \\
\text { set }\end{array}$ & Interval \\
\hline Fast & {$[0,16]$} \\
Slow & {$[10,22]$} \\
Very & {$[16,25]$} \\
slow & \\
\hline
\end{tabular}

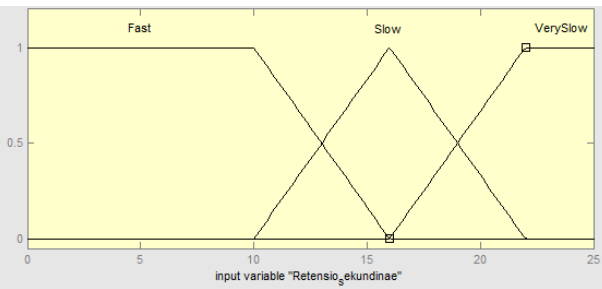

Figure 8. Fuzzy Sets Membership Functions Retensio Sekundinae
p-ISSN : 1858-3911, e-ISSN : 2614-5405

https://journal.uniku.ac.id/index.php/ilkom

$$
\mu_{\text {Fast }}[x]\left\{\begin{array}{rc}
1, & x \leq 10 \\
\frac{16-x}{6}, & 10<x<16 \\
0, & x \geq 16
\end{array}\right.
$$

$$
\mu_{\text {Slow }}[x]\left\{\begin{array}{rc}
0, & x \leq 10 \\
\frac{x-10}{6}, & 10<x<16 \\
1, & x=16 \\
\frac{22-x}{6}, & 16<x<22 \\
0, & x \geq 22
\end{array}\right.
$$

$$
\mu_{\text {Very Slow }}[x]\left\{\begin{array}{cc}
0, & x \leq 16 \\
\frac{x-16}{6}, & 16<x<22 \\
1, & 22 \leq x \leq 25
\end{array}\right.
$$

- Fungsi keanggotaan dari variabel leleran

Table 5. Linguistic Terms Used For Input

\begin{tabular}{cc}
\multicolumn{2}{c}{ Variable Purulent } \\
\hline $\begin{array}{r}\text { Fuz } \\
\text { zy set }\end{array}$ & Interval \\
\hline clea & {$[0,5]$} \\
$\mathbf{r}$ & \\
$\mathbf{l y m}$ & {$[3,7]$} \\
$\mathbf{p h}$ & \\
fester & \\
pus & {$[5,10]$}
\end{tabular}

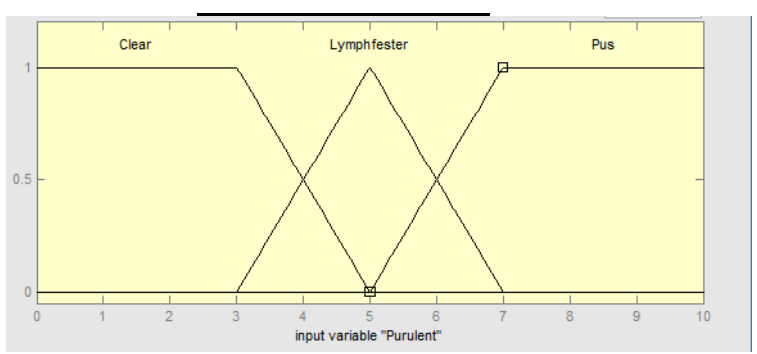

Figure 9. Fuzzy Sets Membership Functions Purulent

$$
\begin{gathered}
\mu_{\text {Clear }}[x]\left\{\begin{array}{cc}
1, & x \leq 3 \\
\frac{5-x}{2}, & 3<x<5 \\
0, & x \geq 5
\end{array}\right. \\
\mu_{\text {Lymphfester }}[x]\left\{\begin{array}{cc}
0, & x \leq 3 \\
\frac{x-3}{2}, & 3<x<5 \\
1, & x=5 \\
\frac{7-x}{2}, & 5<x<7 \\
0, & x \geq 7
\end{array}\right.
\end{gathered}
$$


JURNAL NUANSA INFORMATIKA

Volume 13 Nomor 1, Januari 2019

$$
\mu_{\text {Pus }}[x]\left\{\begin{array}{cc}
0, & x \leq 5 \\
\frac{x-5}{2}, & 5<x<7 \\
1, & 7 \leq x \leq 10
\end{array}\right.
$$

- $\quad$ Fungsi keanggotaan dari variabel urinasi

Table 6. Linguistic Terms Used For Input

\begin{tabular}{cc}
\multicolumn{2}{c}{ Variable Urinate } \\
\hline $\begin{array}{c}\text { Fuzzy } \\
\text { set }\end{array}$ & Interval \\
\hline Rarely & {$[0,6]$} \\
Normal & {$[3,9]$} \\
Often & {$[6,10]$} \\
\hline
\end{tabular}

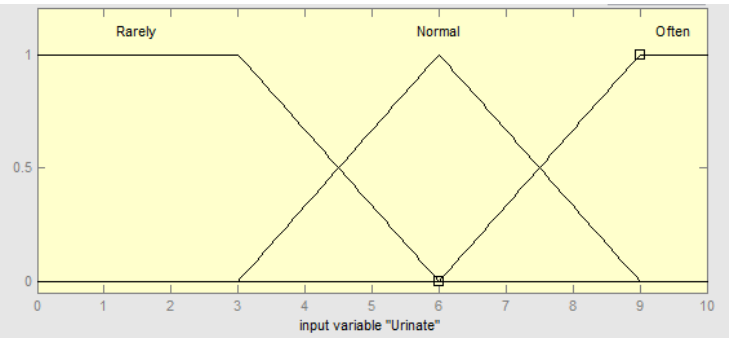

Figure 10. Fuzzy Sets Membership Functions Urinate

$$
\mu_{\text {Reraly }}[x]\left\{\begin{array}{cc}
1, & x \leq 3 \\
\frac{6-x}{3}, & 3<x<6 \\
0, & x \geq 6
\end{array}\right.
$$

$\mu_{\text {Normal }}[x]\left\{\begin{array}{cc}0, & x \leq 3 \\ \frac{x-3}{3}, & 3<x<6 \\ 1, & x=6 \\ \frac{9-x}{3}, & 6<x<9 \\ 0, & x \geq 9\end{array}\right.$

$\mu_{\text {often }}[x]\left\{\begin{array}{cc}0, & x \leq 8 \\ \frac{x-6}{3}, & 6<x<9 \\ 1, & x \geq 9\end{array}\right.$

(13)

- Fungsi keanggotaan dari variabel lochia Table 7. Linguistic Terms Used For Input

\begin{tabular}{cc}
\multicolumn{2}{c}{ Variable Lochia } \\
\hline $\begin{array}{c}\text { Fuzzy } \\
\text { set }\end{array}$ & Interval \\
\hline Short & {$[4,15]$} \\
Normal & {$[10,20]$} \\
\hline
\end{tabular}

p-ISSN : 1858-3911, e-ISSN : 2614-5405

https://journal.uniku.ac.id/index.php/ilkom

$\overline{\text { Long } \quad[15,25]}$

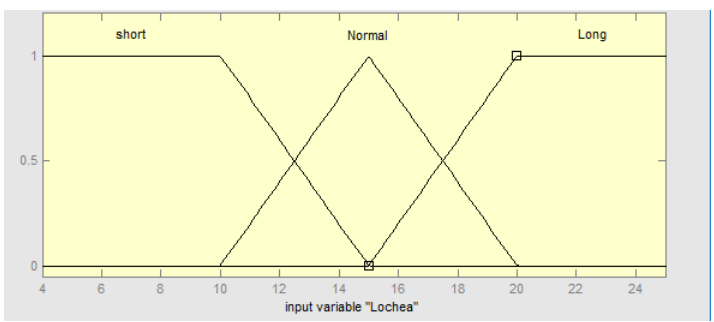

Figure 11. Fuzzy Sets Membership Functions Lochea

$$
\begin{array}{r}
\mu_{\text {pendek }}[x]\left\{\begin{array}{cc}
1, & x \leq 10 \\
\frac{15-x}{5}, & 10<x<15 \\
0, & x \geq 15
\end{array}\right. \\
\mu_{\text {normal }}[x]\left\{\begin{array}{rc}
\frac{(14)}{0,} & x \leq 10 \\
\frac{x-10}{5}, & 10<x<15 \\
\frac{20-x}{5}, & 15<x<20 \\
0, & x \geq 20
\end{array}\right.
\end{array}
$$

$$
\mu_{\text {panjang }}[x]\left\{\begin{array}{cc}
0, & x \leq 15 \\
\frac{x-15}{5}, & 15<x<20 \\
1, & x \geq 20
\end{array}\right.
$$

Table 8. Linguistic Terms Used For Output Variable Classification Endometritis

\begin{tabular}{cc}
\hline $\begin{array}{c}\text { Fuzzy } \\
\text { set }\end{array}$ & $\begin{array}{c}\text { Interva } \\
\mathbf{l}\end{array}$ \\
\hline mild & {$[0-50]$} \\
symptoms \\
severe & {$[30-70]$} \\
symptoms & \\
Acute & {$[50-$} \\
& $100]$ \\
\hline
\end{tabular}

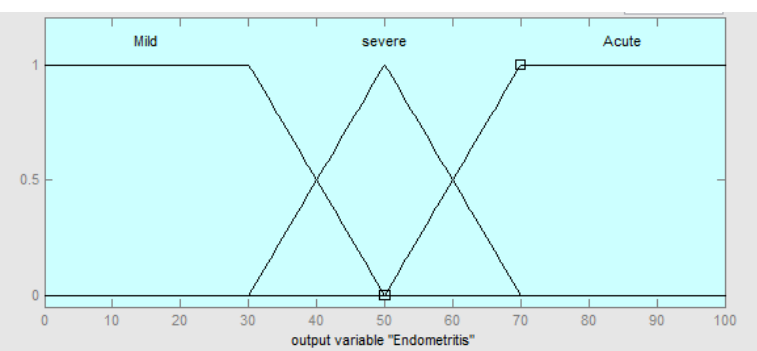

Figure 12. Fuzzy Sets Membership Functions Output Variable Endometritis

\subsection{Inferensi fuzzy}


JURNAL NUANSA INFORMATIKA

Volume 13 Nomor 1, Januari 2019

Sistem inferensi fuzzy menerima input crisp. Input ini kemudian dikirim ke basis pengetahuan yang terdiri dari 324 aturan fuzzy dalam bentuk IF-THEN. nilai keanggotaan anteseden atau $\alpha$ akan dicari pada setiap aturan. Apabila aturan lebih dari satu, maka akan dilakukan agregasi semua aturan.

\section{3. defuzzyfikasi}

Selanjutnya pada hasil agregasi akan dilakukan defuzzy untuk mendapatkan nilai crisp sebagai output sistem. Teknik yang dipakai untuk defuzzifikasi menggunakan Metode ratarata terpusat (Center Average DefFuzzyfier).

\section{Results And Discussion}

Pada awal proses menjalankan aplikasi, aplikasi akan menampilkan menu utama yang berisi tombol diagnosa, tindakan, bantuan dan profil. Untuk memulai diagnosa pengguna harus memilih tombol diagnosa, selanjutnya Aplikasi akan menampilkan enam pertanyaan, untuk melihat hasil diagnosa, pengguna harus memilih tombol proses. Tampilan dari aplikasi dapat dilihat pada Gambar 13.

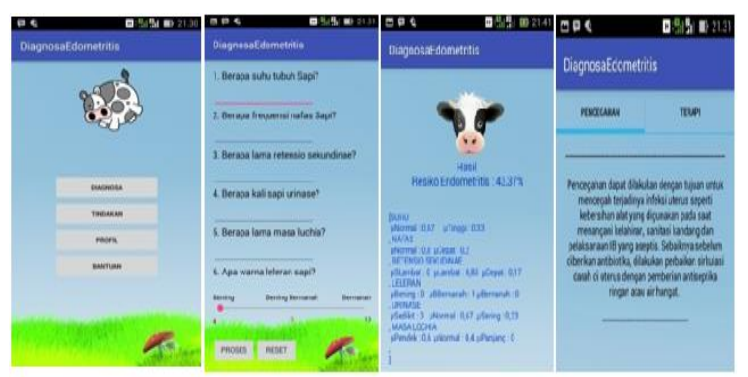

Figure 13. Mobile Application User Interface

\subsection{Testing Validasi}

Untuk mengevaluasi kinerja sistem, menggunakan pengujian dengan meng-input nilai yang terdapat dalam rentang variabel dan diluar rentang variabel, hasil ditunjukkan pada tabel 9.

Table 9. Validation Testing

\begin{tabular}{ccccc}
\hline $\mathbf{N}$ & Name & Expecte & Results & Conclusio \\
o & Tests & $\begin{array}{c}\text { d } \\
\text { obtained }\end{array}$ & n \\
& & results & & \\
\hline 1 & Valid & System & The & Valid \\
& Input & $\begin{array}{l}\text { accordin } \\
\text { g to the }\end{array}$ & system is & \\
& & processin & \\
& & methods & g well & \\
\hline
\end{tabular}

p-ISSN : 1858-3911, e-ISSN : 2614-5405

https://journal.uniku.ac.id/index.php/ilkom

\begin{tabular}{|c|c|c|c|c|}
\hline 2 & $\begin{array}{l}\text { Invali } \\
d \\
\text { input }\end{array}$ & $\begin{array}{l}\text { The } \\
\text { system } \\
\text { does not } \\
\text { process } \\
\text { the data } \\
\text { does not } \\
\text { match }\end{array}$ & $\begin{array}{l}\text { The } \\
\text { system } \\
\text { does not } \\
\text { process }\end{array}$ & Valid \\
\hline
\end{tabular}

\subsection{Testing Akurasi}

Pengujian akurasi digunakan untuk menentukan kinerja aplikasi dalam mendiagnosis penyakit. Data diambil dari 12 sampel, hasil yang diperoleh dari sistem perhitungan, kemudian dicocokkan dengan hasil analisis ahli. Keakuratan hasil tes dapat dilihat pada Tabel 10.

Table 10. Accuracy Testing

\begin{tabular}{|c|c|c|c|c|c|c|c|c|c|}
\hline 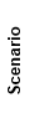 & 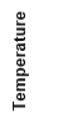 & 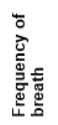 & 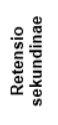 & 节 & 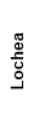 & $\begin{array}{l}\overline{\tilde{E}} \\
\frac{\vec{\omega}}{\bar{E}} \\
\bar{a}\end{array}$ & 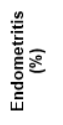 & 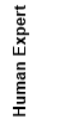 & 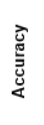 \\
\hline 1 & 40 & 34 & 6 & 8 & 21 & 3 & 50 & Severe & 1 \\
\hline 2 & 37 & 42 & 1 & 6 & 13 & 3 & 39,6 & Mild & 1 \\
\hline 3 & 38 & 34 & 8 & 7 & 6 & 5 & 43,76 & Mild & 1 \\
\hline 4 & 38 & 41 & 12 & 9 & 14 & 3 & 40,92 & Mild & 1 \\
\hline 5 & 38 & 31 & 8 & 8 & 15 & 4 & 54,14 & Severe & 1 \\
\hline 6 & 38 & 36 & 2 & 6 & 10 & 3 & 39,6 & Mild & 1 \\
\hline 7 & 39 & 40 & 16 & 9 & 12 & 7 & 44 & Mild & 1 \\
\hline 8 & 39 & 41 & 9 & 6 & 15 & 3 & 41,11 & Mild & 1 \\
\hline 9 & 40 & 37 & 14 & 9 & 21 & 7 & 42,45 & Mild & 1 \\
\hline 10 & 38 & 37 & 18 & 10 & 12 & 4 & 46,41 & Mild & 1 \\
\hline 11 & 39 & 39 & 1 & 10 & 22 & 7 & 43,17 & Mild & 1 \\
\hline
\end{tabular}

$$
\text { Accuracy value }=\frac{\text { Number of accurate data }}{\text { Number all data }}
$$

$$
\text { Accuracy value }=\frac{12}{12} \times 100 \%=100
$$

\section{Kesimpulan}

Logika fuzzy dapat bermanfaat karena merupakan cara yang efektif dan akurat untuk mendeskripsikan persepsi manusia terhadap persoalan pengambilan keputusan. Penggunaan Metode Fuzzy Tsukamoto dapat diterapkan untuk diagnosis endometritis berdasarkan gejala Suhu, Frekuensi nafas, Retensio sekundinae, Leleran, Urinasi dan Masa lochia. Hasil penelitian menunjukkan bahwa sistem berjalan cukup baik dari perbandingan 12 contoh hasil dari pakar dan sistem menunjukkan nilai $100 \%$ akurat.

\section{Daftar Pustaka}

[1] G L Astiti, (2010). Petunjuk Praktis Manajemen Pencegahan dan Pengendalian Penyakit pada Ternak sapi. NTB. NTB, 2010. 
JURNAL NUANSA INFORMATIKA

Volume 13 Nomor 1, Januari 2019

[2] J Giarratano and G Riley, Expert System Principles and Programming. Boston: PWS Publishing, 2005.

[3] E Turban, Decision Support and Expert Systems: Management Support Systems, Fourth Edition. United States of America: Prentice-Hall, Inc, 1995.

[4] E Setyarin, D Putra, and A Purnawan, "The Analysis of Comparison of Expert System of Diagnosing Dog Disease by Certainty Factor Method and Dempster-Shafer Method.," IJCSI, pp. 578-584, 2013.

[5] Ch.Viswanadha Sarma, "Rule Based Expert System for Rose Plant ," International Journal of Engineering Research \& Technology (IJERT), pp. 1-9, 2012.

[6] Munirah, Suriawati, and Teresa, "Design and Development of Online Dog Diseases Diagnosing System Vol. 6, No. 11," International Journal of Information and Education Technology, pp. 913-1915, 2015.

[7] Nestorovic, "Dog Disease expert System," Annals of DAAAM for 2010 \& Proceedings of the 21 st International DAAAM Symposium, 2010.

[8] wahyu Ardianto, Wiwik Anggraeni, and Ahmad Mukhlason, "Pembuatan Sistem Pakar Untuk Pendeteksian dan Penanganan Dini Pada Penyakit Sapi Berbasis Mobile Android Dengan Kajian Kinerja Teknik Knowledge Representation," JURNAL TEKNIK ITS Vol. 1, pp. 310-315, 2012.

[9] Abdul Talib Bon and Silvia Firda Utami, An analytical hierarchy process and fuzzy inference system tsukamoto for production planning: a review and conceptual research.: Department of Production and Operations Management, Faculty of Technology Management and B, 2014.

[10] J.S.R Jang, chuen tsai sun, and eiji mizutani, Neuro fuzzy and soft computing acomputational approach to learning and machine intelligence. London: Prentice Hall, 1997.

[11] J E Manspeaker, "Metritis and Endometritis, Dairy Integrated Reproductive Management," Maryland, 2016.

[12] Irfan Subakti, Sistem Berbasis Pengetahuan. Surabaya: Institut Teknologi Sepuluh Nopember, 2006.

[13] A Sunari, Strategi dan Kebijakan dalam
p-ISSN : 1858-3911, e-ISSN : 2614-5405

https://journal.uniku.ac.id/index.php/ilkom

Percepatan Pencapaian Swasembada Daging Sapi 2014. Jakarta: Direktorat Pangan dan Pertanian BAPPENAS, 2010.

[14] Lia Daoliang, Fua Zetian, and Yanqing Duan, "Fish Expert a web-based expert system for fish disease diagnosis," Expert Systems with Applications, p. 23, 2002.

[15] Darma Putra, Eka Setyarini, and Adi Purnawan, "The Analysis of Comparison of Expert System of Diagnosing Dog Disease by Certainty Factor Method and Dempster-Shafer," International Journal of Computer Science Issues, pp. 576-584, 2013. 